\title{
PCOS in adolescence: effect of metformin on menstrual irregularities
}

\author{
Bhavana V. Sontakke* \\ Department of Obstetrics and Gynecology, Dr. Panjabrao Deshmukh Memorial Medical College, Amravati, \\ Maharashtra, India
}

Received: 26 May 2017

Revised: 09 June 2017

Accepted: 24 June 2017

\section{*Correspondence:}

Dr. Bhavana V. Sontakke,

E-mail: drbhavanasontakke@gmail.com

Copyright: ( $)$ the author(s), publisher and licensee Medip Academy. This is an open-access article distributed under the terms of the Creative Commons Attribution Non-Commercial License, which permits unrestricted non-commercial use, distribution, and reproduction in any medium, provided the original work is properly cited.

\section{ABSTRACT}

Background: PCOS is an endocrine disorder affecting women across lifespan, initially a disease of the females in the child bearing age group, nowadays maximum adolescent females also present with PCOS. Adolescence PCOS is a heterogenous endocrine disorder diagnosed in 5\% to $10 \%$ of adolescent girls and is one of the major causes of adolescent hyperandrogenism and menstrual irregularity. Thus, this study was carried out to study the effect of Metformin on adolescent patients with PCOS on Weight reduction and Regularization of Menstrual cycle. Secondary objective is to study the occurrences of various manifestations in patients with PCOS.

Methods: Patients aged 10-20 years diagnosed PCOS attending the outpatient department of OBGY over a period of two years were included in the study. Out of 100 patients, 20 patients were excluded because of other causes of anovulation viz thyroid abnormalities, prolactin level abnormalities and patients who did not turn up for follow up. Study was done on 80 patients of PCOS. Patients were divided into two groups A and B. Group A $(n=40)$ received $500 \mathrm{mgs}$ Metformin and Group B $(\mathrm{n}=40)$ received placebo. Results were analysed using statistical package of social sciences (SPSS) 21.0. Statistical significance was set at $\mathrm{p} \leq 0.05$.

Results: In the present study Irregular cycle was the commonest occurring menstrual irregularity. Menstrual Cycle was regularised in $95 \%$ of the study group while only 35\% of the control group. $85 \%$ patients in the present test group had lost weight at the end of 6 months while only 55\% in the control group had lost weight in 6 months. Thus A 6 month course of metformin improves menstrual cyclicity in women with the PCOS.

Conclusions: In patients with PCOS, the addition of insulin sensitizers viz metformin along with diet and lifestyle modifications has resulted in significant weight loss and improvement in cyclicity of menstrual cycle. Thus, Insulinsensitizing agents provide a rational approach to the treatment of the metabolic and endocrine abnormalities in PCOS women

Keywords: Adolescent PCOS, Menstrual irregularities, Metformin

\section{INTRODUCTION}

PCOS is an endocrine disorder affecting almost in $5 \%$ to $10 \%$ of women. Initially thought to be a disease of the females in the child bearing age group but nowadays seen frequently adolescent females. The condition was first described in 1935 by Stein IF and Leventhal ML, hence its original name of Stein-Leventhal syndrome. ${ }^{1}$
PCOS in one of the major causes of adolescent hyperandrogenism and menstrual irregularity. ${ }^{2}$

PCOS is characterized by a complex set of symptoms, the outward signs and symptoms of the disease are as a result of hyperandrogenism. This occurs due to overproduction of testesterone from ovarian thecal cells as well as adrenal glands. Hyperandrogenism in such females 
manifest as hirsutism, acne, frontal and temporal balding, deepening of voice, increased muscle mass, decreased breast size. In severe cases virilization involving clitoromegaly may occur. More than one third of women presenting to a dermatology clinic with acne are diagnosed to have PCOS. Premature adrenarce and hirsutism that occur before puberty have been associated with PCOS in adolescents. ${ }^{2}$ Research to date suggests that Majority of patients with PCOS have insulin resistance. ${ }^{3}$ Their elevated insulin levels contribute to or cause the abnormalities seen in the hypothalamic-pituitary-ovarian axis that lead to PCOS.

Other names for this syndrome include:

- Polycystic Ovarian Syndrome

- Polycystic Ovary Disease (PCOD)

- Functional Ovarian Hyperandrogenism

- Stein-Leventhal Syndrome

Two definitions are commonly used:

1. In 1990 a consensus workshop sponsored by the NIH/NICHD suggested that a patient has PCOS if she has

- $\quad$ signs of androgen excess (clinical or biochemical),

- oligoovulation, and

- other entities are excluded that would cause polycystic ovaries.

2. In 2003 a consensus workshop sponsored by ESHRE/ASRM in Rotterdam indicated PCOS to be present if 2 out of 3 criteria are met:

- oligoovulation and/or anovulation,

- excess androgen activity,

- polycystic ovaries (by ultrasound), and other endocrine disorders are excluded.

\section{Pathogenesis}

Polycystic Ovaries develop when the ovaries are stimulated to produce excessive amounts of testosterone. In PCOS, the insulin receptors for carbohydrate metabolism are muted but the insulin receptor on ovarian theca cells are not compromised. Hence in PCOS subjects, the hyperinsulinemic state causes chronic theca cell stimulation and leads to hyperandrogenemia. ${ }^{4}$ Moreover, the biological chronic hyperandrogenemia through its inhibition of hepatic synthesis of IGF -1 binding protein (IGF-1BP) increase the circulation of free form of biologically active IGF-1.

The free IGF-1 could either bind to the LH receptor in the theca cells to amplify the LH action in ovarian mechanism leading to hyperandrogenic biological expression in the hyperinsulinemia induced suppression of hepatic synthesis of SHBG that results in free form of testosterone in circulation. Hence control of insulin levels in the body proves to be logical therapeutic option with the dual benefit of improved reproductive performance and decreased incidence of hyperinsulinemia related metabolic diseases such as hypertension, obesity and atherosclerosis. Insulin sensitizing agents (ISAs) such as biguanides and thiazolidinedione group of drugs, have thus revolutionized the management of PCOS, with higer success rate and pregnancy salvage in infertile subjects.

Hyperinsulinemia could be controlled either by nonpharmacological or pharmacological insulin sensitizer, or preferably by combining both. The nonpharmacological strategy includes exercise, reduced carbohydrate intake, weight control and consumption of vegetables with antioxidants and phytomedicine. Till recently the pharmacological approach essentially relied up on improving the insulin receptor function and the insulin sensitivity employing various insulin sensitizing drugs.

Metformin known for decreasing hepatic gluconeogenesis and thiazolidinedione group of drugs (eg. rosiglitazone) which enhance peripheral utilization of glucose have been the favourite choice. Recent study strongly suggested that PCOS result from the body's failure to use insulin properly and efficiently, which could be due to D- chiro inosital deficiency ${ }^{5}$ which causes defective intracellular metabolism of glucose and thus insulin resistance in PCOS.

The pathophysiology in the D- chiro inositol administration, argues strongly for the physiological significance of this novel signaling system in the control of glucose metabolism. ${ }^{5}$

Inositol phosphoglycan (IPG) generation following insulin action is a significant signaling mechanism. ${ }^{5}$ Tho separate IPG species containing D- chiro inosital and myoinositol have been identified. Almost all the inositol in nature is myo-inositol. Specifically, hyperinsulinemia increases GnRH pulse frequency, LH over FSH dominance, increased ovarian androgen production, decreased follicular maturation, and decreased SHBG binding; all these steps lead to the development of PCOS.

Thus, the aim of the present study is to demonstrate the effect of oral hypoglycaemic drug, Insulin Sensitizer metformin on adolescent patients with PCOS.

\section{METHODS}

This study is performed on patients of age group of 10 to 20 years, attending the outpatient Department of Obstetrics and Gynecology, Lisie hospital, kaloor, cochin; over a period of 2 years.

A total of 80 patients are studied, all diagnosed to have PCOS, of which 40 patients form the test group (Group A) receive metformin, the remaining 40 form the control 
group (Group B) receive either placebos viz iron supplements etc or no treatment.

\section{Inclusion criteria}

Diagnosed Cases of PCOS, based on the criteria defined by European society of human reproduction and embryology (ESHRE) and the American society of reproductive medicine (ASRM)

The guidelines include the following three criteria

- Irregular or absent ovulation

- Clinical or biochemical signs of hyperandrogenism. ${ }^{6-}$

- Polycystic ovaries on ultrasound scan. ${ }^{9}$

Thus, patients with menstrual irregularities (irregular cycles, oligomenorrhea, secondary amenorrhea, polymenorrhea) are included. Patients with Hirsutism, any grade is included. ${ }^{6,7,8}$ Patients with ultrasonographic diagnosis of PCOS are included.

\section{Exclusion criteria}

Patients with other causes of oligoovulation or anovulation

- Hypothyroidism

- Hyperprolactnemia

- Hyperadrenalism

- Androgen secreting tumors etc

- Late or adult onset CAH.

1. Menstrual abnormalities are defined according to the criteria used by Kovac et al in their study on adolescent PCOS.

- Regular cycles: the cycle length between 22 days to 35 days.

- Secondary ammenorhea: the cycle length is more than 180 days or 6 months.

- Irregular cycles: average length of the cycle between 21 days to 41 days but more than 2 cycles of less than 21 days or more than 41 days

- Oligomenorrhea: cycle length of 42 -180 days to 6 months.

2. Hyperandrogenism is characterized by hirsutism, acne etc Hirsutism is assessed as per the FERRIMAN GALLWEY scoring system. ${ }^{6}$

\section{Polycystic ovaries on ultrasound scan}

The morphology of polycystic ovaries has been refined as an ovary with 12 or more follicles measuring $2-9 \mathrm{~mm}$ in diameter and/or increased volume (more than $10 \mathrm{~cm}^{3}$ ) with one ovary being sufficient for diagnosis.
In the presence of a dominant follicle $(>10 \mathrm{~mm})$ or a corpus luteum, the scan should be repeated in the next cycle.

- A thorough general as well as systemic examination of the patients is done on the first visit.

- Baseline blood counts, urine analysis, thyroid profile, prolactin levels, LFT are done.

- Height, weight is noted.

- $\quad$ BMI (body mass index; quetlet index) is calculated.

- $\quad$ Other features are noted ${ }^{10}$

i. Thyroids (to r/o goiter, hypothyroidism)

ii. Breasts (to r/o galactorrhoea)

iii. Waist to hip ratio ( $>0.8$ considered significant)

iv. Hirsutism (ferriman gallwey scoring)

v. Acne.

vi. Acanthosis nigricans (to look for insulin resistance)

Patients are randomly classified into two groups

- Group A (test)

- Group B (control)

All patients are counseled about the occurrence of menstrual irregularities during adolescence and the association of menstrual irregularities with PCOS, nature of the syndrome and the need for weight reduction and lifestyle modification.

Diet control is by prescribing high protein, low carbohydrate diet, at least three light meals per day which are low in sugar and fat and high in fruit, fresh vegetables and salad.

Light sustained exercise such as walking, cycling or swimming for at least an hour at a time several times per week.

Group A is started on metformin [glycomet/diamet]. ${ }^{11}$ Initially a dose of $500 \mathrm{mg}$ daily is given and then the dose is increased gradually.

Group B is given placebos viz some iron supplements. Monthly follow up, for 6 months is done. Occurence of any adverse effects with metformin is noted.

At the end of 6 months, patients are assessed as regards to

- Regularization of menstrual cycle.

- Reduction in body weight.

$5 \%$ or more than $5 \%$ weight loss is considered significant

\section{Statistical analysis}

Data of each patient was entered in MS Excel sheet and was analyzed using statistical package of social sciences (SPSS) 21.0. Statistical significance was set at $\mathrm{p} \leq 0.05$. 


\section{RESULTS}

In the present study $56.25 \%$ of patients belong to the early adolescent age group, $35 \%$ belong to the mid adolescence age group, while $12.5 \%$ are in the late adolescent age group. A total of $76.25 \%$ patients had menarche at $12-13$ years, $23.75 \%$ patients had menarche at $14-16$ years, $83.75 \%$ patients came complaining of irregular periods, $8.75 \%$ had menorhaggia, $5 \%$ had secondary amenorrhea while $2.5 \%$ had polymenorrhea.

Table 1: Distribution according to age.

\begin{tabular}{|c|c|c|c|c|}
\hline Age & Test & Control & Total & $\begin{array}{l}\mathbf{P} \\
\text { value }\end{array}$ \\
\hline $\begin{array}{l}\text { Early } \\
\text { adolescence }\end{array}$ & $\begin{array}{l}23 \\
(57.5 \%)\end{array}$ & $\begin{array}{l}22 \\
(55 \%)\end{array}$ & $\begin{array}{l}45 \\
(56.25 \%)\end{array}$ & \multirow{4}{*}{$0.554^{\mathrm{NS}}$} \\
\hline $\begin{array}{l}\text { Mid } \\
\text { adolescence }\end{array}$ & $\begin{array}{l}14 \\
(35 \%)\end{array}$ & $\begin{array}{l}12 \\
(30 \%)\end{array}$ & $\begin{array}{l}26 \\
(35 \%)\end{array}$ & \\
\hline $\begin{array}{l}\text { Late } \\
\text { adolescence }\end{array}$ & $\begin{array}{l}03 \\
(7.5 \%)\end{array}$ & $\begin{array}{l}06 \\
(15 \%)\end{array}$ & $\begin{array}{l}10 \\
(12.50 \%)\end{array}$ & \\
\hline Total & $\begin{array}{l}40 \\
(100 \%)\end{array}$ & $\begin{array}{l}40 \\
(100 \%)\end{array}$ & $\begin{array}{l}80 \\
(100 \%)\end{array}$ & \\
\hline
\end{tabular}

$57.5 \%$ of test and $55 \%$ of control patients belong to the early adolescence age group. $35 \%$ and $30 \%$ respectively from the test and control are in the mid adolescence. $7.5 \%$ from test and $15 \%$ from control are in the late adolescence

Thus, irregular cycle was the commonest occurring menstrual irregularity and $95 \%$ patients showed regularisation of menses.

Table 2: Distribution according to age at menarche.

\begin{tabular}{|c|c|c|c|c|}
\hline $\begin{array}{l}\text { Age at } \\
\text { menarche }\end{array}$ & Test & Control & Total & $P$ value \\
\hline 12 years & $\begin{array}{l}15 \\
(37.5 \%)\end{array}$ & $\begin{array}{l}14 \\
(35 \%)\end{array}$ & $\begin{array}{l}29 \\
(36.25 \%)\end{array}$ & \multirow{5}{*}{$0.5141^{\mathrm{NS}}$} \\
\hline 13 years & $\begin{array}{l}18 \\
(45 \%)\end{array}$ & $\begin{array}{l}14 \\
(35 \%)\end{array}$ & $\begin{array}{l}32 \\
(40 \%)\end{array}$ & \\
\hline 14 years & $\begin{array}{l}05 \\
(12.5 \%)\end{array}$ & $\begin{array}{l}07 \\
(17.5 \%)\end{array}$ & $\begin{array}{l}12 \\
(15 \%)\end{array}$ & \\
\hline $\begin{array}{l}15 \text { and } 16 \\
\text { years }\end{array}$ & $\begin{array}{l}2 \\
(5 \%)\end{array}$ & $\begin{array}{l}5 \\
(12.5 \%)\end{array}$ & $\begin{array}{l}7 \\
(8.75 \%)\end{array}$ & \\
\hline Total & $\begin{array}{l}40 \\
(100 \%)\end{array}$ & $\begin{array}{l}40 \\
(100 \%)\end{array}$ & $\begin{array}{l}80 \\
(100 \%)\end{array}$ & \\
\hline
\end{tabular}

$82.5 \%$ of patients in the test group and $70 \%$ in the control group have their menarche at 12-13 yrs of age. Menarche at 14-16 yrs is seen in $17.5 \%$ of test and $30 \%$ of patients in control group. $\mathrm{P}$ value $0.51412>0.8$ indicates there is no relation between the two variables.

The results of this study suggest that the addition of insulin sensitizers viz metformin along with diet and lifestyle modifications has resulted in significant weight loss and improvement in cyclicity of menstrual cycle. ${ }^{12}$

Thus Insulin-sensitizing agents provide a rational approach to the treatment of the metabolic and endocrine abnormalities in PCOS women

In this study $56 \%$ had BMI more than $25 \mathrm{~kg} / \mathrm{m}^{2}$ whereas the remaining $44 \%$ were lean PCOS.
Table 3: Distribution of patients according to menstrual irregularities.

\begin{tabular}{|c|c|c|c|}
\hline $\begin{array}{l}\text { Menstrual } \\
\text { irregularities }\end{array}$ & Test & Control & Total \\
\hline Oligomenorrhoea & $\begin{array}{l}0 \\
(0 \%)\end{array}$ & $\begin{array}{l}0 \\
(0 \%)\end{array}$ & $\begin{array}{l}0 \\
(0 \%)\end{array}$ \\
\hline Irregular periods & $\begin{array}{l}36 \\
(90 \%)\end{array}$ & $\begin{array}{l}31 \\
(77.5 \%)\end{array}$ & $\begin{array}{l}67 \\
(83.75 \%)\end{array}$ \\
\hline Polymenorrhoea & $\begin{array}{l}01 \\
(2.5 \%)\end{array}$ & $\begin{array}{l}01 \\
(2.5 \%)\end{array}$ & $\begin{array}{l}02 \\
(2.5 \%)\end{array}$ \\
\hline $\begin{array}{l}\text { Secondary } \\
\text { ammenorrhoea }\end{array}$ & $\begin{array}{l}02 \\
(5 \%)\end{array}$ & $\begin{array}{l}02 \\
(5 \%)\end{array}$ & $\begin{array}{l}04 \\
(5 \%)\end{array}$ \\
\hline Menorhaggia & $\begin{array}{l}01 \\
(2.5 \%)\end{array}$ & $\begin{array}{l}06 \\
(7.5 \%)\end{array}$ & $\begin{array}{l}07 \\
(8.75 \%)\end{array}$ \\
\hline Total & $\begin{array}{l}40 \\
(100 \%)\end{array}$ & $\begin{array}{l}40 \\
(100 \%)\end{array}$ & $\begin{array}{l}80 \\
(100 \%)\end{array}$ \\
\hline
\end{tabular}

$90 \%$ in test group and $77 \%$ in the control group have irregular periods with the total occurnce being around $83.75 \%$. Menorhaggia is seen in $8.75 \%$ of total patients. Polymenorrhea and secondary amenorrhea occurring in $7.5 \%$ cases.

Table 4: According to regularisation of menses after 6 months.

\begin{tabular}{|c|c|c|c|c|}
\hline $\begin{array}{l}\text { Menses } \\
\text { regularised }\end{array}$ & Test & Control & Total & P value \\
\hline Yes & $\begin{array}{l}38 \\
(95 \%)\end{array}$ & $\begin{array}{l}14 \\
(35 \%)\end{array}$ & $\begin{array}{l}52 \\
(65 \%)\end{array}$ & \multirow{3}{*}{$0.0001 \mathrm{~S}$} \\
\hline No & $\begin{array}{l}2 \\
(5 \%)\end{array}$ & $\begin{array}{l}26 \\
(65 \%)\end{array}$ & $\begin{array}{l}28 \\
(35 \%)\end{array}$ & \\
\hline Total & $\begin{array}{l}40 \\
(100 \%)\end{array}$ & $\begin{array}{l}40 \\
(100 \%)\end{array}$ & $\begin{array}{l}80 \\
(100 \%)\end{array}$ & \\
\hline
\end{tabular}

Here $95 \%$ of patients in the test group had regular menstrual cycle at the end of 6 months, only 35\% of patients in control group had regularization of menstrual cycle after 6 months. In this case $p$ value $(0.0001)<0.05$ indicates that there is some relation between the two variables.
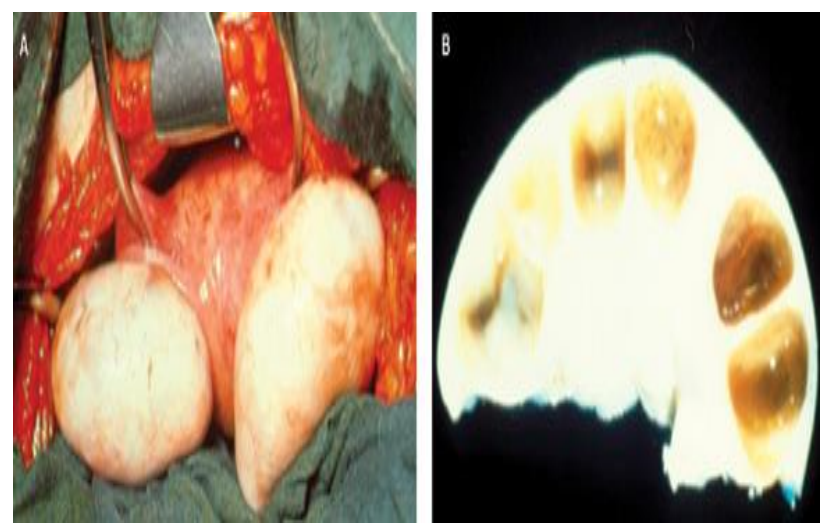

Figure 1: A. Polycystic ovaries, showing increased size and a smooth white surface reflecting thickening of the capsule. B. Section through polycystic ovary, showing multiple cysts with diameter $<10 \mathrm{~mm}$ arranged around the periphery of the ovary.

Weight loss with metformin occurred in obese as well as lean PCOS patients, though the incidence of weight loss was higher in obese patients. 


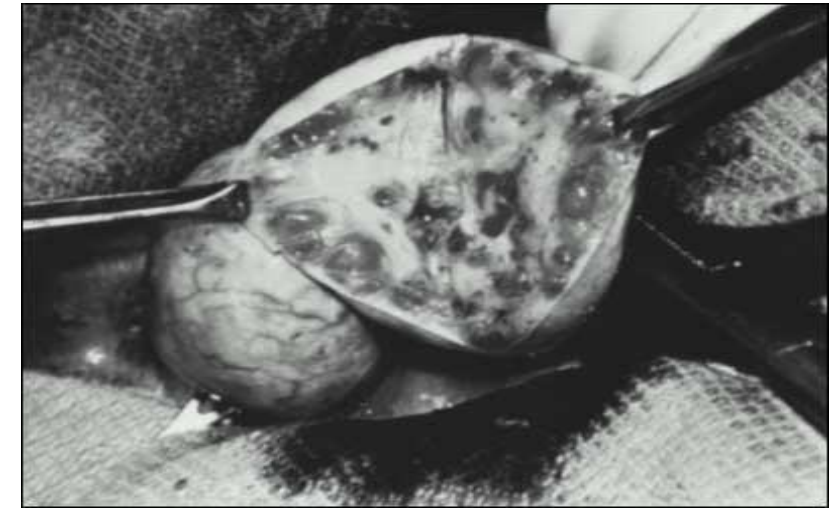

Figure 2: Gross and cut appearance of typical polycystic ovaries. Multiple small follicular cysts are apparent in the cut section

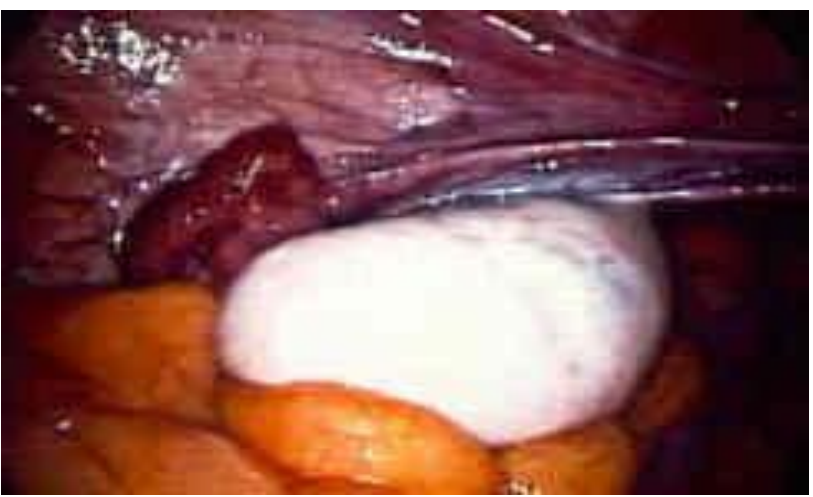

Figure 3: Laparoscopic view: polycystic ovary.

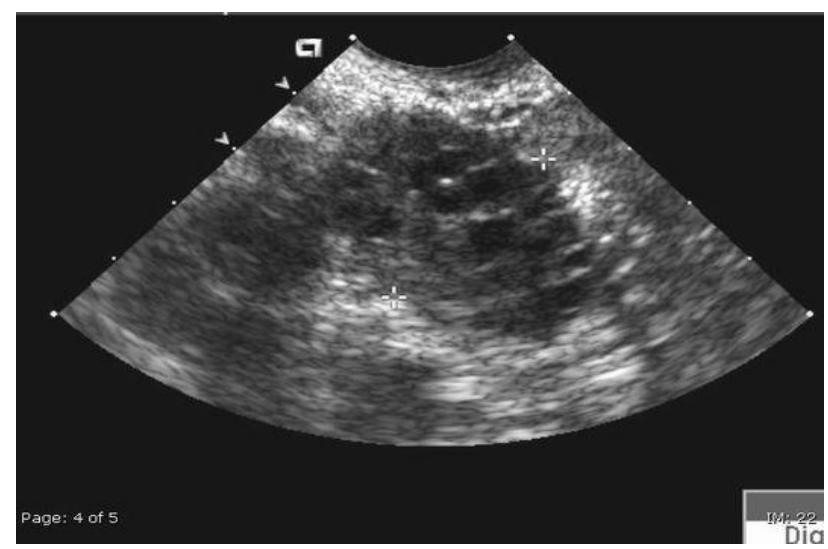

Figure 4: Ultrasound scan: Polycystic ovary-pearl necklace sign.

Weight loss was seen more in patients with grade 2 hirsutism as against grade1 hirsutism. The loss of weight was gradual. For obese PCOS women weight loss of more than $5 \%$ of pretreatment weight restores menstrual regularity in $89 \% .{ }^{13}$ A 6-month course of metformin improves menstrual cyclicity in women with the PCOS.

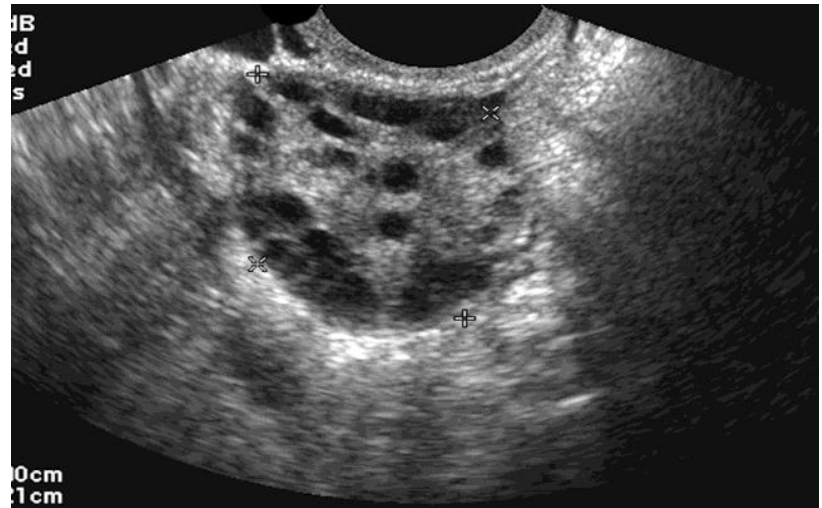

Figure 5: String of pearls.

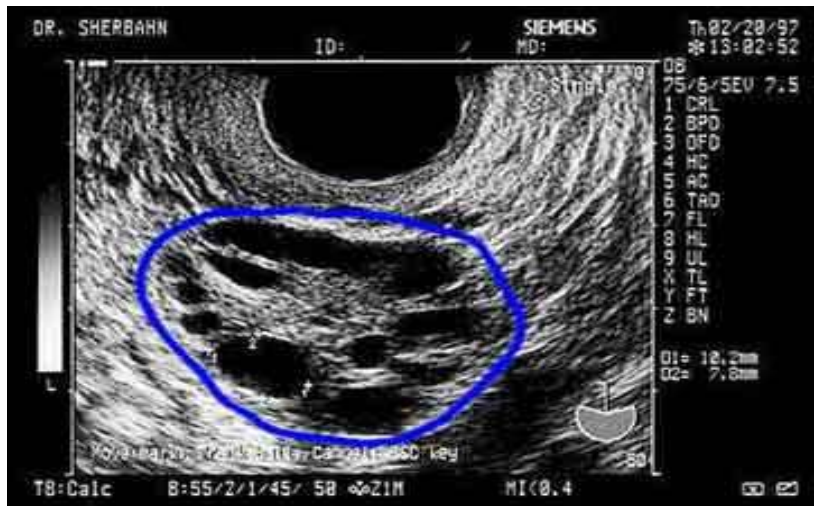

Figure 6: Polycystic ovaries.

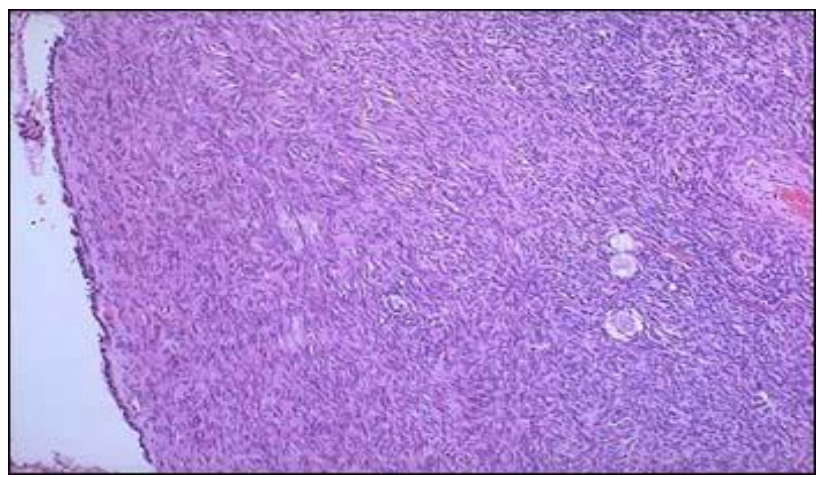

Figure 7: Polycystic ovary, high power view.

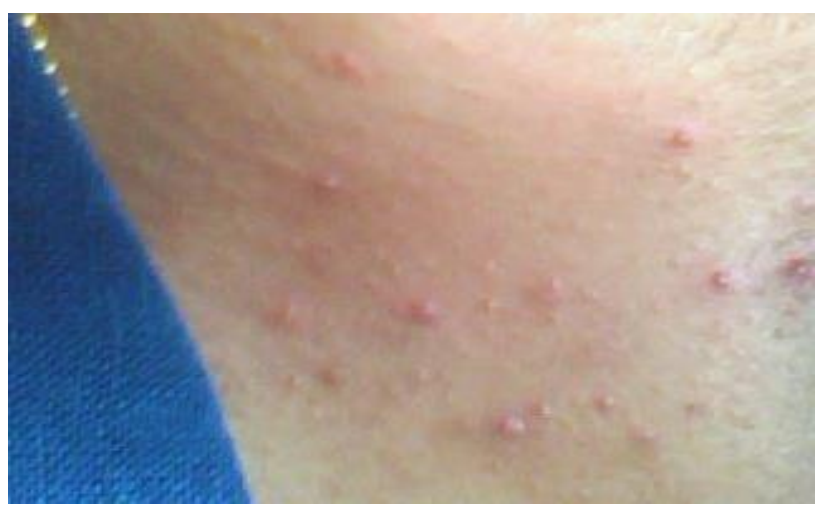

Figure 8: Acne in patients with PCOS 


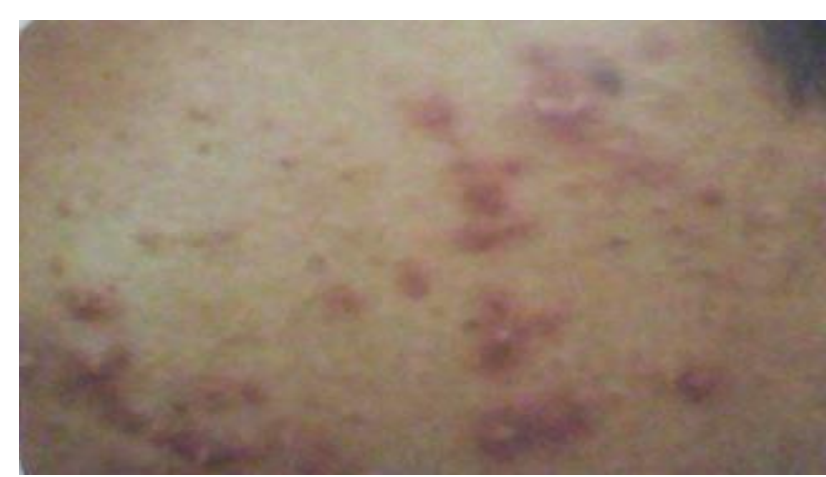

Figure 9: Acne on chest.

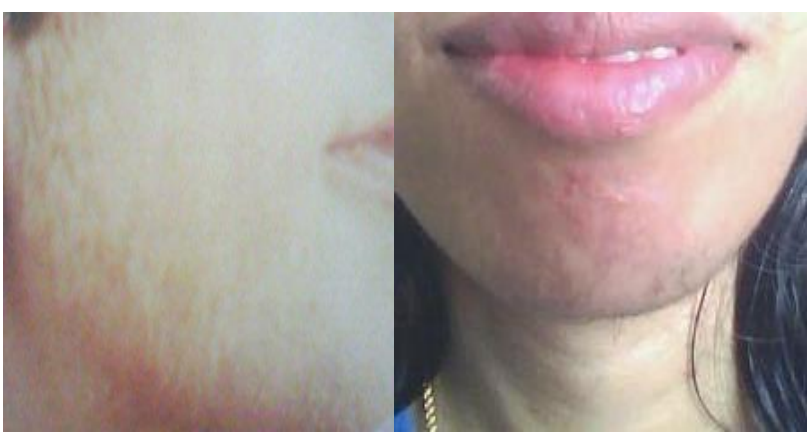

Figure 10: Hirsutism in patient with PCOS

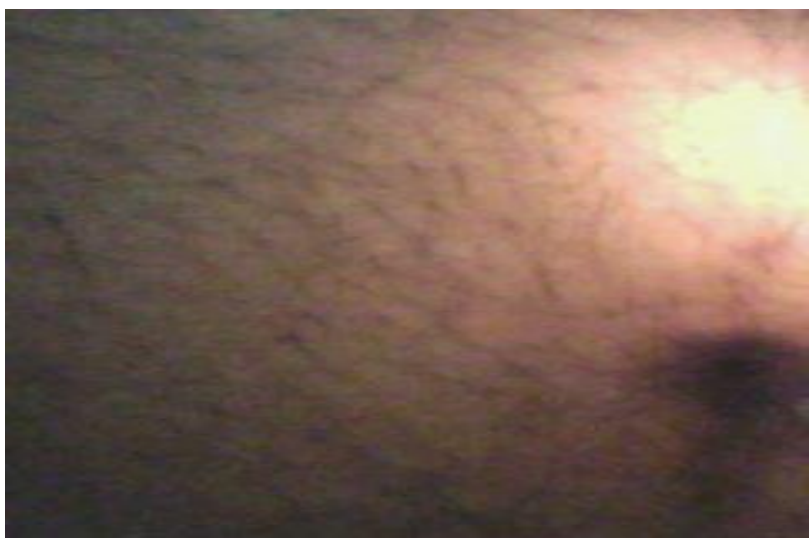

Figure 11: Hair growth on abdomen.

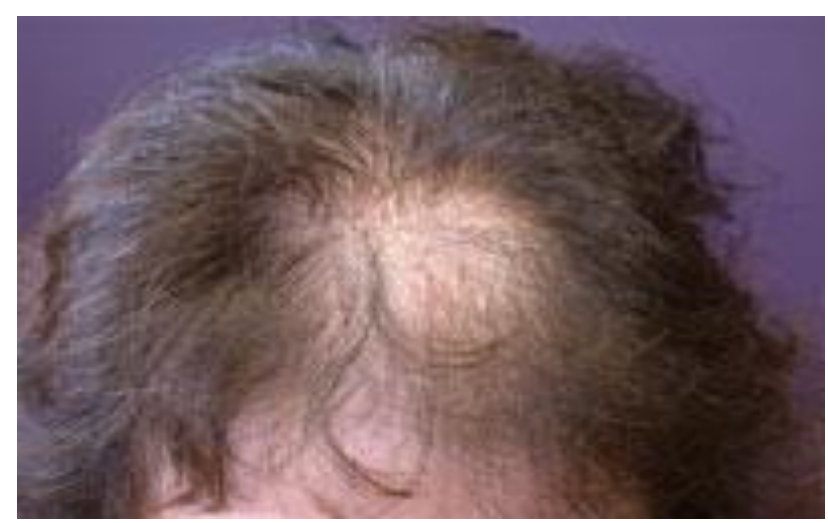

Figure 12: Baldness in patients with PCOS.

\section{DISCUSSION}

This study demonstrates the usefulness of metformin therapy in achieving menstrual cyclicity in the majority of women in our population within six months. The same has been reported in some western studies previously. ${ }^{14}$

Oral contraceptives and anti-androgens have been the mainstay of treatment of PCOS, but as the women in this study with oligo/amenorrhea are in the adolescence age group, metformin is a better option as it helps women to regularize the menstrual cycle through its effect on the underlying pathology viz. insulin resistance. This was proved by regularization of menstrual cycle as well as significant weight reduction and in our study group after metformin treatment. ${ }^{15}$

Most of the compared studies were observational studies, in which metformin was administered to women with PCOS, with recording of biochemical and clinical effects before and during treatment. The end-points studied varied from clinical benefits viz. regularisation of menstrual cycle, decreased hirsutism to effects on ovulation and pregnancy. Almost all studies were of short duration (4-6 months at most); the clinical effects of metformin may take longer to be fully manifest. ${ }^{15}$ Most publications indicate improvement in spontaneous menstruation in $20 \%-50 \%$ of women.

One important study by Kolodziejczyk B et al randomly allocated women to therapy with metformin or conventional therapy for normalising menstrual activity and reducing androgen excess. ${ }^{15}$ This study showed reductions in body weight, insulin levels and androgens with metformin, but an increase in glucose intolerance with the conventional therapy. Similar results were seen in our study where the study group which was given metformin for a period of 6 months showed a significant reduction in weight and improvement in menstrual regularity as compared to the control group receiving placebo.

Two important randomised, double-blind, placebocontrolled trials of metformin therapy in women with PCOS by Moghetti $\mathrm{P}$ et al and Pasquali $\mathrm{R}$ et al have recently been published. ${ }^{16,17}$ In one, 23 women with PCOS randomly allocated to treatment with either placebo or metformin for six months showed significant benefits in menstrual pattern, ovulation rate, insulin sensitivity, and serum free testosterone levels, without changes in body weight. ${ }^{16}$

Almost $50 \%$ of the women involved developed ovulatory cycles, and thus regular menses during an open-label, long-term extension of the study. In the other, 20 women with obesity and PCOS and 20 with obesity only were randomly assigned to either placebo or metformin therapy for six months. Metformin reduced visceral fat mass and improved hirsutism and menstrual pattern in those with PCOS. ${ }^{17}$ 
In the present study $56.25 \%$ of patients belong to the early adolescent age group, $35 \%$ belong to the mid adolescence age group, while $12.5 \%$ are in the late adolescent age group.

Driscoll DA et al studied the occurrence of PCOS in adolescence and found that about $60 \%$ of adolescent PCOS belong to the early adolescent age group similar to that seen in present study. ${ }^{18}$ Ibanez L et al studied the post pubertal Girls with a history of premature pubarche and functional ovarian hyperandrogenism and found that adolescent patients with PCOS have menarche at an early age (12-13 yrs), which is similar to the results in our study where a total of $76.25 \%$ patients had menarche at 12-13 yrs. ${ }^{19}$ Remaining $23.75 \%$ patients had menarche at 14-16 yrs. Arthur et al studied the occurrence of irregular cycles in $92 \%$, secondary amenorrhea in $7 \%$ of patients with PCOS.

In my study $83.75 \%$ patients came complaining of irregular periods, $8.75 \%$ had menorhaggia, 5\% had secondary amenorrhea while $2.5 \%$ had polymenorrhea. Thus, irregular cycle was the commonest occurring menstrual irregularity, which was in accordance to that observed by Arthur et al. 58.75\% patients in my study had grade 1 hirsutism, $16.25 \%$ patients had grade 2 hirsutism. Thus, a total of $75 \%$ of patients with PCOS in this study had either grades of hirsutism which is similar to that seen by Dunaif et al. ${ }^{20}$ Dunaif et al studied the occurrence of hirsutism in $77.7 \%$ of patients with PCOS. ${ }^{20}$

Timpatanapong $\mathrm{P}$ et al studied hormonal profiles and prevalence of polycystic ovary syndrome in women with acne in1997 and documented frequent association of acne in women with PCOS. ${ }^{21} 83.75 \%$ of patients in this study had acne which is similar to the results obtained by Timpatanapong $\mathrm{P}$ et al. ${ }^{21}$

$85 \%$ patients in the present test group had lost weight at the end of 6 months while only $55 \%$ in the control group had lost weight in 6 months. Weight loss of more than $5 \%$ was considered significant.

In this study $56 \%$ had BMI more than $25 \mathrm{~kg} / \mathrm{m}^{2}$ whereas the remaining $44 \%$ were lean PCOS. Weight loss with metformin occurred in obese as well as lean PCOS patients, though the incidence of weight loss was higher in obese patients. The loss of weight was gradual.

These results were similar to study by Tang $\mathrm{T}$ et al who conducted a Combined lifestyle modification and metformin in obese patients with polycystic ovary syndrome, which was a randomized, placebo- controlled, double-blind multicentre study and proved that Metformin along with diet and lifestyle modification is better effective than diet and lifestyle modification alone. $^{22}$
Kolodziejczyk B et al studied and suggested that, Metformin reduces the endocrinopathy of PCOS, allowing resumption of normal menses in most (91\%) women with PCOS. Similar results were obtained in this study where $95 \%$ of the study group while only $35 \%$ of the control group had regular cycles at the end of 6 months. A 6-month course of metformin improves menstrual cyclicity in women with the PCOS.

Insulin-sensitizing agents provide a rational approach to the treatment of the metabolic and endocrine abnormalities in PCOS women. Diamanti-Kandarakis E, Zapanti $\mathrm{E}$ studied the effect of insulin sensitizers and found metformin to be effective in regularization of menses. ${ }^{23} 42.5 \%$ patients in this study had minor side effects with metformi intake viz GI upset, malaise and nausea.None had major complications while $57.5 \%$ patients tolerated the drug well and had no side effects.

Metformin therapy was well tolerated by the majority of our patients which is consistent with other studies. Homburg R Apr studied the adverse effects of metformin and found the commonest to be GI upset such as flatulence and other major complications to be rare. ${ }^{24}$

Thus, Metformin proves to be a very excellent option along with lifestyle modifications and weight loss for regularizing menstrual irregularities in Adolescent patients with PCOS.

\section{Funding: No funding sources \\ Conflict of interest: None declared \\ Ethical approval: Not required}

\section{REFERENCES}

1. Stein IF, Leventhal ML. Amenorrhoea associated with bilateral polycystic ovaries. Am J Obstet Gynecol. 1935;29:181.

2. Driscoll DA. Polycystic ovary syndrome in adolescence. Ann NY Acad Sci. 2003;997:49-55.

3. Archard C, Theirs J. Le virilisme pilaire et son association a L'insufficiency glycolytique (diabetes des femmes a barbe). Bull Acad Nat Med. 1921;86:51

4. Nestler JE. Role of hyperinsulinemia in the pathogenesis of polycystic ovary syndrome, and its clinical implications, seminars. Reprod Endocrinol. 1997;15:111-122.

5. Nestler JE, Jakubowicz DJ, Reamer P, Gunn RD, Allan G. Ovulatory and metabolic effects of D-chiroinositol in the polycystic ovary syndrome. N Engl J Med. 1999;340(17):1314-20.

6. Ferriman D, Gallwey JD. Clinical assessment of body hair growth in women. J Clin Endocrinol Metab. 1961;21:1440-7.

7. Carey AH, Chan KL, Short F, White DM, Williamson R, Frank S. Evidence for a single gene effect in polycystic ovaries and male pattern baldness. Clin Endocrinol. 1993;38:653. 
8. Cortet-Rudelli C, Dewailly D. Diagnosis of hyperandrogenism in female adolescents. hyperandrogenism in adolescent girls. Armenian Health Network, Health.am. Retrieved on 2006.

9. Balen AH, Laven JSE, Tan SL, Dewailly D. The ultrasound assessment of the polycystic ovary; international consensus definations. Human Reprod Update. 2003;9:505-14.

10. Balen AH1, Conway GS, Kaltsas G, Techatrasak K, Manning PJ, West C et al. Polycystic Ovary Syndrome, the spectrum of disorder in 1741 patients. Hum Reprod. Hum Reprod. 1995;10(8):2107-11.

11. Kirpichnikov D, McFarlane SI, Sowers JR. Metformin: an update. Ann Intern Med. 2002;137(1):25-33.

12. La Marca A, Artensio AC, Stabile G, Volpe A. Metformin treatment of PCOS during adolescence and the reproductive period. Eur J Obstet Gynecol Reprod Biol. 2005;121(1):3-7

13. Tang T, Glanville J, Hayden CJ, White D, Barth JH, Balen AH. Combined lifestyle modification and metformin in obese patients with polycystic ovary syndrome: A randomized, placebo- controlled, double-blind multicentre study. Hum Reprod. 2005;21(1):80-9.

14. Glueck CJ, Wang P, Fontaine R, Tracy T, SieveSmith L. Metformin-induced resumption of normal menses in 39 of $43(91 \%)$ previously amenorrheic women with the polycystic ovary syndrome. Metabolism. 1999;48(4):511-9

15. Kolodziejczyk B, Duleba AJ, Spaczynski RZ, Pawelczyk L. Metformin therapy decreases hyperandrogenism and hyperinsulinemia in women with polycystic ovary syndrome. Fertil Steril. 2000;73:1149-54.

16. Moghetti P, Castello R, Negri C, Tosi F, Perrone F, Caputo $\mathrm{M}$ et al. Metformin effects on clinical features, endocrine and metabolic profiles, and insulin sensitivity in polycystic ovary syndrome: a randomised, double-blind, placebo-controlled 6 month trial, followed by open, long-term clinical evaluation. J Clin Endocrinol Metab. 2000;85:13946.
17. Pasquali R, Gambineri A, Biscotti D, Vicennati V, Gagliardi L, Colitta D et al. Effects of long-term treatment with metformin added to hypocaloric diet on body composition, fat distribution, and androgen and insulin levels in abdominally obese women with and without polycystic ovary syndrome. J Clin Endocrinol Metab. 2000;85:2767-74.

18. Driscoll DA, Ann NY. Polycystic Ovary Syndrome in Adolescence. Acad Sci. 2003;997:49-5521.

19. Ibanez L, Potau N, Zampolli M, Prat N, Virdis $\mathrm{R}$, Vicens-calvet $\mathrm{E}$ et al. Hyperinsulinemia in post pubertal Girls with a history of premature pubarche and functional ovarian hyperandrogenism. J clin Endocrinol Metab. 1996;81:1237-43.

20. Dunaif A, Scott D, Finegood D, Quintana B, Whitcomb R. The insulin-sensitizing agent troglitazone improves metabolic and reproductive abnormalities in the polycystic ovary syndrome. J Clin Endocrinol Metab. 1996;81:3299-306.

21. Timpatanapong P, Rojanasakul A. Hormonal [rofiles and prevalence of polycystic ovary syndrome in women with acne. J Dermatol. 1997;24(4):223-9.

22. Tang T, Glanville J, Hayden CJ, White D, Barth JH, Balen AH. Combined life-style modification and metformin in obese patients with polycystic ovary syndrome (PCOS). Arandomised, placebocontrolled, double-blind multi-centre study. Hum Reprod. 2006;21:80-9.

23. Diamanti-Kandarakis E, Kouli C, Tsianateli TA. Therapeutic effects of metformin on insulin resistance and hyperandrogenism in polycystic ovary syndrome. Eur J Endocrinol. 1998;138(3):269-74.

24. Homburg R. Should patients with polycystic ovarian syndrome be treated with metformin? A note of cautious optimism. Hum Reprod. 2002;17(4):853-6).

Cite this article as: Sontakke BV. PCOS in adolescence: effect of metformin on menstrual irregularities. Int J Reprod Contracept Obstet Gynecol 2017;6:3490-7. 